\title{
Singularity Analysis for Three Materials Junctions
}

\author{
Tian Shuai \\ Mechanical Engineering College, \\ Yangzhou University \\ Yangzhou, P. R. China \\ metianshuai@163.com
}

\author{
Yazhou $\mathrm{Xu}$ \\ Mechanical Engineering College, \\ Yangzhou University \\ Yangzhou, P. R. China \\ yazhouxu@163.com
}

\author{
Zhixue $\mathrm{Wu}$ \\ Mechanical Engineering College, \\ Yangzhou University \\ Yangzhou, P. R. China \\ zhixue_wu@yahoo.com
}

\begin{abstract}
The eigenvalue $\lambda$ is an important parameter to represent the stress singularity on the singular point of dissimilar linear elastic material wedges. An Airy stress function method has been used to calculate eigenvalues of the bi-material and trimaterial junctions by varying an interface angle $\theta_{1}$ from $0-180^{\circ}$ respectively. For the three material junctions, with the aiding of the method, the stress and displacement distribution around the singular point have been obtained for double real eigenvalues.
\end{abstract}

Keywords-stress intensity; interface strength; three materials; angular function; eigenvalue

\section{INTRODUCTION}

Stress singularities exist on the vertex of the bi or multimaterial junctions, consisting of dissimilar, homogeneous, isotropic and linear elastic solids. The singularity mainly caused by the discontinuous of geometry or the mechanical properties of the material. In many engineering practices, singularity stress existed on the point that several materials meet maybe the initiation of fracture prone to occur. It has been proven that the order of the stress singularities can be a function of the Young's modulus, Poisson's ratio, geometry and the boundary conditions along the surface edges. Some analytical methods that focused on the stress singularities had been reported. Williams [1] used the Airy stress function method analyzed singular stress field on the single material wedge vertex. Yang and Munz [2] used the similar method analyzed stress intensity factors near the bi-material bonded edge. Bogy[3,4], Hein and Erdogan[5] used the Mellin transform method examined stress singularities on bi-material joined wedge. England [6] used the complex potential method examined stress singularities influenced by different type boundary conditions. Stern and Soni [7], Carpenter and Byers [8] used a path independent integral formula computed the intensity of stress singularity at the fixed-free corners and bimaterial notches respectively. The order of stress singularities on the bi-material or multi-material wedges or junctions could be real or complex numbers. Different kinds of eigenvalue represent different stress singularities. Munz and Yang [9] examined stress singularities of bi-material edges with two real eigenvalues. Cho and Carpenter [10], Dempsey and Sinclair [11] analyzed the power-logarithmic stress singularities for bimaterial and multi-material wedges respectively.

The present paper uses the Airy stress function to solve eigenvalues of stress singularities on the vertex of bi- and trimaterial junctions. It has been known that eigenvalue is a

The present work was supported by the National Natural Science Foundation of China under Grant No. 51075354 function of Young's modulus and interface angle. In this article sequence, eigenvalues affected by varying interface angle is first considered. And then talks about the angular function of the stress and displacement around the singular points.

\section{FORMULATION}

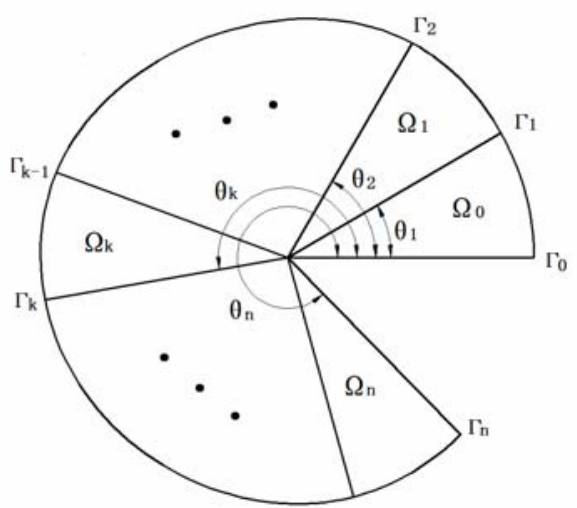

Fig.1 Multi-material model

As shown in Fig 1, the general geometry consisting of dissimilar, homogeneous, isotropic, and linear elastic material wedge under a plain strain state is considered. The interface between different material sectors is perfectly bonded and the $\mathrm{v}$-notch is stress free on the edges. The Young's modulus is $\mathrm{E}_{\mathrm{m}}$ and Poisson's ratio is $v_{\mathrm{m}}$ for the sector $\Omega_{\mathrm{m}}$. The interface $\Gamma_{\mathrm{m}}$ is between sectors $\Omega_{\mathrm{m}}$ and $\Omega_{\mathrm{m}+1}$. The stress and displacement of singular field can be obtained by the Airy stress function.

$$
\begin{aligned}
& \sigma_{\theta \theta}^{m}=r^{\lambda_{k}-1} \lambda_{k}\left(\lambda_{k}+1\right)\left[A_{m} \sin \left(\lambda_{k}+1\right) \theta+B_{m} \cos \left(\lambda_{k}+1\right) \theta\right. \\
& \left.+C_{m} \sin \left(\lambda_{k}-1\right) \theta+D_{m} \cos \left(\lambda_{k}-1\right) \theta\right] \\
& \sigma_{r \theta}^{m}=r^{\lambda_{k}-1}\left(-\lambda_{k}\right)\left\{\left(\lambda_{k}+1\right)\left[A_{m} \cos \ell_{k}+1\right) \theta-B_{m} \sin \left(\ell_{k}+1\right) \theta\right] \\
& \left.\left.+\left(\lambda_{k}-1\right)\left[C_{m} \cos \ell_{k}-1\right) \theta-D_{m} \sin \left(\ell_{k}-1\right) \theta\right]\right\} \\
& \sigma_{r r}^{m}=r^{\lambda_{k}-1}\left\{-\lambda_{k}\left(\lambda_{k}+1\right)\left[A_{m} \sin \left(\ell_{k}+1\right) \theta+B_{m} \cos \left(_{k}+1\right) \theta\right]\right. \\
& \left.\left.-\lambda_{k}\left(\lambda_{k}-3\right)\left[C_{m} \sin \left(\lambda_{k}-1\right) \theta+D_{m} \cos \ell_{k}-1\right) \theta\right]\right\} \\
& 2 \mu_{m} u_{r r}^{m}=r^{\lambda_{k}}\left\{-\left(\lambda_{k}+1\right)\left[A_{m} \sin \left(\ell_{k}+1\right) \theta+B_{m} \cos \ell_{k}+1\right) \theta\right] \\
& \left.\left.+\left(3-\lambda_{k}-4 v_{m}\right)\left[C_{m} \sin \left(_{k}-1\right) \theta+D_{m} \cos \ell_{k}-1\right) \theta\right]\right\}
\end{aligned}
$$




$$
\begin{aligned}
& \left.2 \mu_{m} u_{\theta \theta}^{m}=r^{\lambda_{k}}\left\{-\left(\lambda_{k}+1\right)\left[A_{m} \cos \ell_{k}+1\right) \theta-B_{m} \sin \ell_{k}+1\right) \theta\right] \\
& \left.\left.\left.+\left(4 v_{m}-3-\lambda_{k}\right)\left[C_{m} \cos \ell_{k}-1\right) \theta-D_{m} \sin \ell_{k}-1\right) \theta\right]\right\}
\end{aligned}
$$

where, $\mu_{\mathrm{m}}=\mathrm{E}_{\mathrm{m}} /\left[2\left(1+v_{\mathrm{m}}\right)\right]$, and $\beta_{\mathrm{m}}$ takes on the value $v_{\mathrm{m}}$ for plain strain and $v_{\mathrm{m}} /\left(1+v_{\mathrm{m}}\right)$ for plain stress.

On perfectly bonded interface $\Gamma_{\mathrm{m}}$, the stress and displacement continuity conditions can be written as:

$$
\begin{gathered}
\mathrm{A}_{\mathrm{m}} \sin (\lambda+1) \theta_{\mathrm{m}}+\mathrm{B}_{\mathrm{m}} \cos (\lambda+1) \theta_{\mathrm{m}} \\
+\mathrm{C}_{\mathrm{m}} \sin (\lambda-1) \theta_{\mathrm{m}}+\mathrm{D}_{\mathrm{m}} \cos (\lambda-1) \theta_{\mathrm{m}}= \\
\mathrm{A}_{\mathrm{m}+1} \sin (\lambda+1) \theta_{\mathrm{m}}+\mathrm{B}_{\mathrm{m}+1} \cos (\lambda+1) \theta_{\mathrm{m}} \\
+\mathrm{C}_{\mathrm{m}+1} \sin (\lambda-1) \theta_{\mathrm{m}}+\mathrm{D}_{\mathrm{m}+1} \cos (\lambda-1) \theta_{\mathrm{m}} \\
(\lambda+1)\left[\mathrm{A}_{\mathrm{m}} \cos (\lambda+1) \theta_{\mathrm{m}}-\mathrm{B}_{\mathrm{m}} \sin (\lambda+1) \theta_{\mathrm{m}}\right] \\
+(\lambda-1)\left[\mathrm{C}_{\mathrm{m}} \cos (\lambda-1) \theta_{\mathrm{m}}-\mathrm{D}_{\mathrm{m}} \sin (\lambda-1) \theta_{\mathrm{m}}\right]= \\
(\lambda+1)\left[\mathrm{A}_{\mathrm{m}+1} \cos (\lambda+1) \theta_{\mathrm{m}}-\mathrm{B}_{\mathrm{m}+1} \sin (\lambda+1) \theta_{\mathrm{m}}\right] \\
+(\lambda-1)\left[\mathrm{C}_{\mathrm{m}+1} \cos (\lambda-1) \theta_{\mathrm{m}}-\mathrm{D}_{\mathrm{m}+1} \sin (\lambda-1) \theta_{\mathrm{m}}\right] \\
\tau_{\mathrm{m}+1, \mathrm{~m}}\left\{-(\lambda+1)\left[\mathrm{A}_{\mathrm{m}} \sin (\lambda+1) \theta_{\mathrm{m}}+\mathrm{B}_{\mathrm{m}} \cos (\lambda+1) \theta_{\mathrm{m}}\right]\right. \\
\left.+\left(3-\lambda-4 v_{\mathrm{m}}\right)\left[\mathrm{C}_{\mathrm{m}} \sin (\lambda-1) \theta_{\mathrm{m}}+\mathrm{D}_{\mathrm{m}} \cos (\lambda-1) \theta_{\mathrm{m}}\right]\right\}= \\
-(\lambda+1)\left[\mathrm{A}_{\mathrm{m}+1} \sin (\lambda+1) \theta_{\mathrm{m}}+\mathrm{B}_{\mathrm{m}+1} \cos (\lambda+1) \theta_{\mathrm{m}}\right] \\
+\left(3-\lambda-4 v_{\mathrm{m}+1}\right)\left[\mathrm{C}_{\mathrm{m}+1} \sin (\lambda-1) \theta_{\mathrm{m}}+\mathrm{D}_{\mathrm{m}+1} \cos (\lambda-1) \theta_{\mathrm{m}}\right] \\
\tau_{\mathrm{m}+1, \mathrm{~m}}\left\{-(\lambda+1)\left[\mathrm{A}_{\mathrm{m}} \cos (\lambda+1) \theta_{\mathrm{m}}-\mathrm{B}_{\mathrm{m}} \sin (\lambda+1) \theta_{\mathrm{m}}\right]\right. \\
\left.+\left(4 v_{\mathrm{m}}-\lambda-3\right)\left[\mathrm{C}_{\mathrm{m}} \cos (\lambda-1) \theta_{\mathrm{m}}-\mathrm{D}_{\mathrm{m}} \sin (\lambda-1) \theta_{\mathrm{m}}\right]\right\}= \\
-(\lambda+1)\left[\mathrm{A}_{\mathrm{m}+1} \cos (\lambda+1) \theta_{\mathrm{m}}-\mathrm{B}_{\mathrm{m}+1} \sin (\lambda+1) \theta_{\mathrm{m}}\right] \\
+\left(4 v_{\mathrm{m}+1}-\lambda-3\right)\left[\mathrm{C}_{\mathrm{m}+1} \cos (\lambda-1) \theta_{\mathrm{m}}-\mathrm{D}_{\mathrm{m}+1} \sin (\lambda-1) \theta_{\mathrm{m}}\right]
\end{gathered}
$$

where, $\tau_{\mathrm{m}+1, \mathrm{~m}}=\mu_{\mathrm{m}+1} / \mu_{\mathrm{m}}, \mu_{\mathrm{m}}=\mathrm{E}_{\mathrm{m}} /\left[2\left(1+v_{\mathrm{m}}\right)\right]$.

On the notch edges (such as $\Gamma_{0}, \Gamma_{\mathrm{n}}$ in fig.1), traction-free conditions can be written as:

$$
\begin{gathered}
A_{m} \sin (\lambda+1) \theta_{m}+B_{m} \cos (\lambda+1) \theta_{m} \\
+C_{m} \sin (\lambda-1) \theta_{m}+D_{m} \cos (\lambda-1) \theta_{m}=0 \\
(\lambda+1)\left[A_{m} \cos (\lambda+1) \theta_{m}-B_{m} \sin (\lambda+1) \theta_{m}\right] \\
+(\lambda-1)\left[C_{m} \cos (\lambda-1) \theta_{m}-D_{m} \sin (\lambda-1) \theta_{m}\right]=0
\end{gathered}
$$

The stress and displacement conditions can be formed a system of matrix equations:

$$
[\mathrm{R}]\{\mathrm{X}\}=\{0\}
$$

$$
\text { where, } \begin{aligned}
\{X\} & =\left\{\mathrm{A}_{1}, \mathrm{~B}_{1}, \mathrm{C}_{1}, \mathrm{D}_{1}, \ldots, \mathrm{A}_{\mathrm{n}}, \mathrm{B}_{\mathrm{n}}, \mathrm{C}_{\mathrm{n}}, \mathrm{D}_{\mathrm{n}}\right\}^{\mathrm{T}} \\
{[\mathrm{R}] } & =\left\{\mathrm{R}_{1, \mathrm{n}}, \mathrm{R}_{2, \mathrm{n}}, \mathrm{R}_{3, \mathrm{n}}, \mathrm{R}_{4, \mathrm{n}}, \ldots, \mathrm{R}_{4 \mathrm{n}-3, \mathrm{n}}, \mathrm{R}_{4 \mathrm{n}-2, \mathrm{n}}, \mathrm{R}_{4 \mathrm{n}-1, \mathrm{n}}, \mathrm{R}_{4 \mathrm{n}, \mathrm{n}}\right\}^{\mathrm{T}}
\end{aligned}
$$

Eigenvalues of stress singularities can be obtained by nontrivial solutions if and only if determinant of [R] equal to zero. The general expansion for stress and displacement field given by the asymptotic expansion:

$$
\begin{aligned}
& \sigma_{i j}(r, \theta)=r^{\lambda_{1}-1} A_{1} f_{i j 1}(\theta)+r^{\lambda_{2}-1} A_{12} f_{i j 2}(\theta)+\ldots \\
& +r^{\lambda_{N}-1} A_{N N} f_{i j N}(\theta)+o(1)
\end{aligned}
$$

$$
\begin{aligned}
& u_{i j}(r, \theta)=r^{\lambda_{1}-1} A_{11} g_{i 1}(\theta)+r^{\lambda_{2}-1} A_{12} g_{i 2}(\theta)+\ldots \\
& +r^{\lambda_{N}-1} A_{1 N} g_{i N}(\theta)+o(1)
\end{aligned}
$$

where, $\lambda_{\mathrm{N}}$ is the Nth eigenvalue on the singular field. Angular functions $\mathrm{f}_{\mathrm{ijN}}(\theta)$ and $\mathrm{g}_{\mathrm{iN}}(\theta)$ are:

$$
\begin{aligned}
& f_{\theta \theta k}^{m}=\lambda_{k}\left(\lambda_{k}+1\right)\left[\frac{A_{m}}{A_{1 k}} \sin \left(\lambda_{k}+1\right) \theta+\frac{B_{m}}{A_{1 k}} \cos \left(\lambda_{k}+1\right) \theta\right. \\
& \left.+\frac{C_{m}}{A_{1 k}} \sin \left(\lambda_{k}-1\right) \theta+\frac{D_{m}}{A_{1 k}} \cos \left(\lambda_{k}-1\right) \theta\right] \\
& f_{r k}^{m}=-\lambda_{k}\left\{\left(\lambda_{k}+1\right)\left[\frac{A_{m}}{A_{1 k}} \cos \left(\lambda_{k}+1\right) \theta-\frac{B_{m}}{A_{1 k}} \sin \left(\lambda_{k}+1\right) \theta\right]\right. \\
& \left.+\left(\lambda_{k}-1\right)\left[\frac{C_{m}}{A_{1 k}} \cos \left(\lambda_{k}-1\right) \theta-\frac{D_{m}}{A_{1 k}} \sin \left(\lambda_{k}-1\right) \theta\right]\right\} \\
& f_{r r k}^{m}=-\lambda_{k}\left(\lambda_{k}+1\right)\left[\frac{A_{m}}{A_{1 k}} \sin \left(\lambda_{k}+1\right) \theta+\frac{B_{m}}{A_{1 k}} \cos \left(\lambda_{k}+1\right) \theta\right] \\
& -\lambda_{k}\left(\lambda_{k}-3\right)\left[\frac{C_{m}}{A_{1 k}} \sin \left(\lambda_{k}-1\right) \theta+\frac{D_{m}}{A_{1 k}} \cos \left(\lambda_{k}-1\right) \theta\right] \\
& g_{r r k}^{m}=\frac{1}{2 \mu_{m}}\left\{-\left(\lambda_{k}+1\right)\left[\frac{A_{m}}{A_{1 k}} \sin \left(\lambda_{k}+1\right) \theta+\frac{B_{m}}{A_{1 k}} \cos \left(\lambda_{k}+1\right) \theta\right]\right. \\
& \left.+\left(3-\lambda_{k}-4 v_{m}\right)\left[\frac{C_{m}}{A_{1 k}} \sin \left(\lambda_{k}-1\right) \theta+\frac{D_{m}}{A_{1 k}} \cos \left(\lambda_{k}-1\right) \theta\right]\right\} \\
& g_{\theta \theta k}^{m}=\frac{1}{2 \mu_{m}}\left\{-\left(\lambda_{k}+1\right)\left[\frac{A_{m}}{A_{1 k}} \cos \left(\ell_{k}+1\right) \theta-\frac{B_{m}}{A_{1 k}} \sin \left(\lambda_{k}+1\right) \theta\right]\right. \\
& \left.\left.+v_{m}-3-\lambda_{k}\right)\left[\frac{C_{m}}{A_{1 k}} \cos \left(\ell_{k}-1\right) \theta-\frac{D_{m}}{A_{k k}} \sin \left(\lambda_{k}-1\right) \theta\right]\right\}
\end{aligned}
$$

where, $A_{1 k}$ is $A_{1}$ in $\{X\}$ for the $k$ th eigenvalue.

\section{CALCULATE EXAMPLES}

\section{A. Eigenvalues}

Tri-material fully bonded junction is shown as Fig 2. It can be seen from figure 2 that the junction composed of one half plane wedge and two wedges coupled with the other half plane. The elastic constants are given by $\mathrm{E}_{1}=70.3 \mathrm{GPa}, v_{1}=0.345$, $\mathrm{E}_{2}=206 \mathrm{GPa}, v_{2}=0.3, \mathrm{E}_{3}=4.93 \mathrm{GPa}, v_{3}=0.33$ respectively. The interface angle are pre-determined as $\theta_{0}=0^{\circ}, \theta_{2}=180^{\circ}, \theta_{3}=360^{\circ}$.

Eigenvalue is calculated by solving the determinant of equation (4) and only in the range of $0<\operatorname{Re} \lambda<1$ that make contribution for the singular stress fields. Figure 3 presents result obtained by varying interface angle $\theta_{1}$ from $0^{\circ}$ to $180^{\circ}$. For the tri-material junction, there are two real values exist with $\theta_{1}$ in $0-108^{\circ}$ and single value with $\theta_{1}$ in $109^{\circ}-180^{\circ}$ as shown by solid lines. The dashed line shown in figure 3 is the eigenvalue of bi-material junction. Bi-material juncton is two wedges bonded together without material 3 and traction free on $\theta_{0}$ and $\theta_{2}$. It is easily to find that there are no singularities with $\theta_{1}$ in the range of $0-52^{\circ}$ and $109^{\circ}-127^{\circ}$. The smallest eigenvalue of 
the bi-material junction is $\lambda=0.831623$ when $\theta_{1}$ in the angle of $160^{\circ}$.

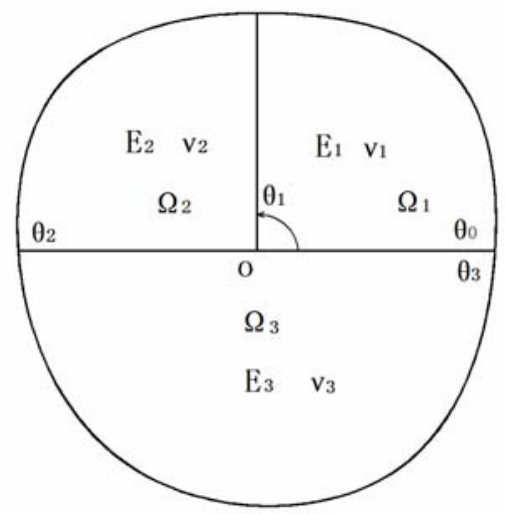

Fig.2 Tri-material model

Compared with the two eigenvalue lines, it can be known that there are still existing stress singularities on the tri-material junction while no singularities existing on the bi-material junction for the interface angle $\theta_{1}$ in the range of $0-52^{\circ}$ and $109^{\circ}-127^{\circ}$. In other words, it is easier to make a less stress singularity junction for the bimaterial junction. The tendency of bi-material junction's eigenvalue is similar as a branch of trimaterial junction's.

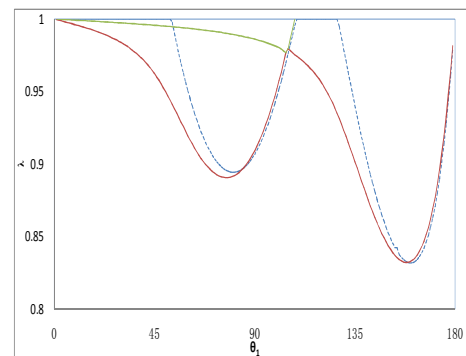

Fig.3 Eigenvalues for bi- and tri-material junctions with varying $\theta_{1}$

\section{B. Angular functions}

There are two eigenvalues for the tri-material junction when interface angle $\theta_{1}$ is selected as $90^{\circ}$ and keep material constants unchanged. Figure 4 and figure 5 show the angular variation functions of the stress and displacement field respectively for the $\lambda_{1}=0.9090285$. In the same way, figure 6 and figure 7 show the angular function $f(\theta)$ and $g(\theta)$ of the stress and displacement field respectively for the $\lambda_{2}=0.9861089$. It can be clearly seen from figure 4 to figure 8 that continuity of stress and displacement are ensured by the continuity of functions $\mathrm{f}_{\mathrm{r} \theta}$, $\mathrm{f}_{\theta \theta}, \mathrm{g}_{\mathrm{rr}}$ and $\mathrm{g}_{\theta \theta}$ at the angles $0^{\circ}, 90^{\circ}, 180^{\circ}$ and $360^{\circ}$ respectively, and the discontinuity in the function $f_{\mathrm{rr}}$ at these same angles. The real stress and displacement value around the singular point can be obtained by multiply $\mathrm{A}_{1 \mathrm{~N}}$ on the corresponding angular functions and added all of them together by equations (5).

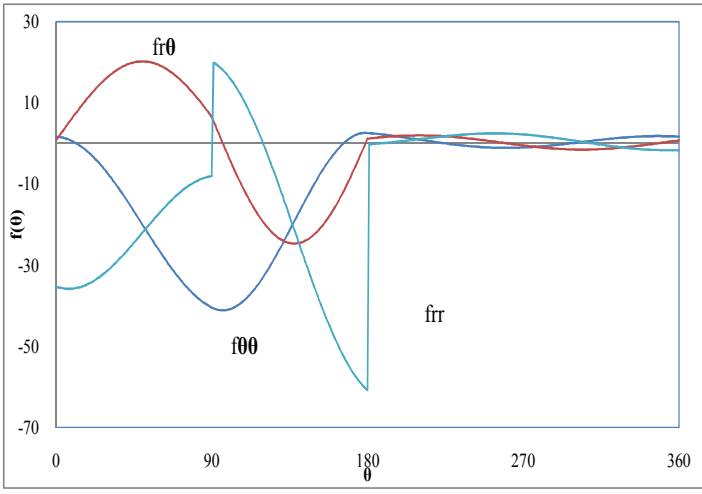

Fig.4 The angular distribution of the stress associated with $\lambda_{1}$

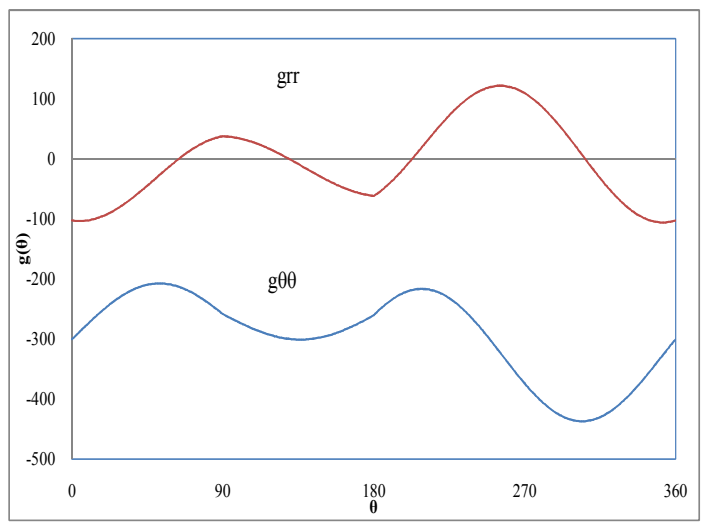

Fig.5 The angular distribution of the displacement associated with $\lambda_{1}$

Compared with the stress functions of figure 4 and figure 6 , the distributions and change tendencies different from each other for different eigenvalues. And stress on the interface angle may not greater than that on basement materials. The displacement angular functions in figure 5 and figure 7, shows that displacement in the softer materials vary more rapidly with $\theta$ varying from 0 to $360^{\circ}$ than in the other two materials.

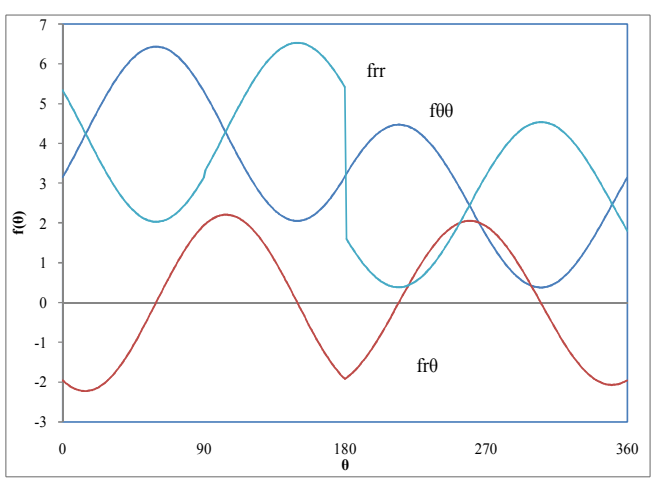

Fig.6 The angular distribution of the stress associated with $\lambda_{2}$ 


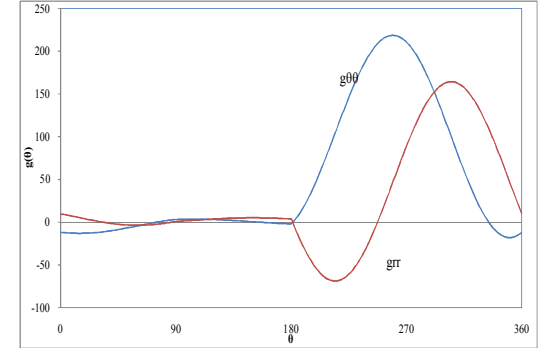

Fig.7 The angular distribution of the displacement associated with $\lambda_{2}$

For the two eigenvalues, $\lambda_{1}(0.9090285)$ is less than $\lambda_{2}$ (0.9861089) but means higher stress singularity on the singular point. The two eigenvalues correspond to different angular functions and different stress intensity factors. Eigenvalue and angular functions can be obtained analytically and the stress intensity factors generally calculated by using the finite element method.

\section{CONCLUSION}

An Airy function method has been used to calculate eigenvalues and angular functions of the dissimilar materials wedges. Eigenvalue is a function of material constants and interface angle, so changing of the interface angle or material constants that will affect eigenvalues of wedges. With the method proposed in this work, it was calculated two realvalued eigenvalues of tri-material junction and correspondingly angular functions. The angular function is a depiction of the stress and displacement distribution around the singular point.
In engineering practice, an appropriate interface angle selection that will improve the strength of the junction.

\section{REFERENCES}

[1] M.L. Williams, "Stress singularities resulting from various boundary conditions in angular comers of plates in extension," ASME Journal of Applied Mechanics, vol. 19, pp. 526-528, 1952.

[2] Y.Y. Yang, D. Munz, Stress singularities in a dissimilar materials joint with edge tractions under mechanical and thermal loadings. Int.J. Solids Strucrures, vol. 34, No. 10, pp.1199-1216, 1997.

[3] D. B. Bogy, "On the Problem of Edge bonded Elastic Quarter-planes Loaded at the Boundary,” Int. J. Solids Structures, vol. 6, pp. 1287-1313, 1970 .

[4] D. B. Bogy, "Two Edge-Bonded Elastic Wedges of Different Materials and Wedge Angles under Surface Tractions," J. Applied Mechanics, vol. 38, pp. 377-386, 1971.

[5] V. L. Hein and F. Erdogan, "Stress Singularities in a Two-material Wedge," Int. J.Fract. Mech., vol. 7, pp. 317-330, 1971.

[6] A. H. England, "On Stress Singularities in Linear Elasticity," Int. J. Engng. Sci., vol. 9, pp. 571-585. 1971,

[7] M. Stern and M. L. Soni, "On the Computation of Stress Intensities at Fixed-free Corners," Int.J. Solids Structures, vol. 12, pp. 331-337, 1976.

[8] W.C. Carpenter and C. Byers, "A Path Independent Integral for Computing Stress Intensities for V-notched Cracks in a Bi-material,” Int. J. Fract., vol. 35, pp, 245-268, 1987.

[9] D. Munz and Y.Y. Yang. "Stresses near the edge of bonded dissimilar materials described by two stress intensity factors," International Journal of Fracture, vol. 60, pp, 169-177, 1993.

[10] S. B. Cho and W. C. Carpenter. "The complex potential approach to power logarithmic stress singularities for v-notched cracks in a bimaterial," KSME International Journal, vol.13, No.1, pp. 19-25,1999

[11] J. E. Dempsey and G. B. Sinclair, "On the stress singularities in the plane elasticity of the composite wedge," Journal of Elasticity, vol. 9, pp, 373-391, 1979. 